\title{
Factors Affecting the Utilization of Food by Dairy Cows
}

\section{Factors Influencing the Rate of Breakdown of Cellulose (Cotton Thread) in the Rumen of the Cow}

\author{
By C. C. BALCH and V. W. JOHNSON \\ National Institute for Research in Dairying, University of Reading
}

(Received 20 fune 1950)

Cotton threads were used by Hoflund, Quin \& Clark (1948) to study the rate of breakdown of cellulose in the rumen of sheep. These workers found that on a basic diet of poor quality grass hay, both cellulose breakdown and appetite were stimulated by small amounts of sugar in the diet, but markedly inhibited by excessive amounts of sugar. Excess casein suddenly introduced into a diet low in protein and carbohydrate caused a marked inhibition of cellulose digestion.

When comparing between-cow differences in digestibility coefficients for crude fibre, Balch (1950) obtained data suggesting that a high ratio of water to dry matter in the total intake, and hence perhaps in the reticulo-ruminal digesta, favoured the breakdown of crude fibre. If so, it might be postulated that breakdown of the constituents of crude fibre would be lower among the dry digesta in the dorsal sac of the rumen than among the more fluid contents of the ventral sac. Confirmation of the importance of fluid conditions in determining the rate of breakdown of crude fibre in the reticulo-rumen would also offer a possible explanation for the depression of the digestibility of crude fibre known to result from the grinding of hay. Balch (1950) showed that this depression of digestibility of fibre was not the result of an accelerated rate of passage of ground hay through the reticulo-rumen.

This communication is an account of studies done with two fistulated cows to check the hypothesis outlined above. The main technique used was a modification of the cotton-thread method of Hoflund et al. (I948), but the results were checked by one trial with hay suspended in the rumen in silk bags.

\section{METHODS}

Cows. The experiments were conducted on two Shorthorn cows with large rumen fistulas; these were the same cows as used in work already reported (Balch, 1950). The fistulas were closed by means of rubber cannulas and bungs of the type described by Balch \& Johnson (1948).

Measurement of breakdown of cotton. The method of measuring the rate of breakdown of cotton in the reticulo-rumen was as follows. The cotton thread used was Clark and Co.'s 'Anchor' button thread purchased from a local drapery store. Lengths of $3 \mathrm{~m}$. were made into coils by winding them round a $250 \mathrm{ml}$. beaker (diameter $6.4 \mathrm{~cm}$.) and binding loosely with the end of the cotton. Numbers of loops made in this way were 
washed in hot $\left(c .90^{\circ}\right)$ running water, dried and weighed separately. After weighing, each coil of thread was supported on nylon suture-material to which was attached a numbered tag (PI. I).

Numbers of coils of cotton were suspended in the rumen by attaching a loop in the supporting suture material to a plaited nylon cord (parachute line) knotted at its lower end to a brass weight ( $\mathrm{r} \mathrm{kg}$.) and at its upper end to the cannula. For experiments involving only the dorsal and ventral sacs of the rumen the distance between the two groups of coils was $45 \mathrm{~cm}$. and the upper group was $15 \mathrm{~cm}$. from the outer flange of the cannula. When a third group of coils was included it was equidistant between the upper and lower groups.

At intervals the nylon cord was withdrawn from the rumen and two coils were removed from the upper and from the lower groups. The remaining coils were immediately replaced in the cow. After removal from the rumen the coils were again thoroughly washed in a stream of hot tap water, dried, removed from the supporting nylon and weighed. The loss of dry matter from the coils was expressed as a percentage of the initial weight. The reliability of the technique may be judged by the fact that when ten coils were suspended in the ventral sac of the rumen of one of the cows (Y) for $24 \mathrm{hr}$., the standard deviation of individual values from a mean loss of $19.1 \%$ was $\pm \mathrm{I} \cdot 6 \%$.

Measurement of breakdown of hay. In two further experiments ground hay was suspended in silk bags in the rumen of a cow being fed on hay and concentrates. In each weighed bag were placed $20 \mathrm{~g}$. hay and the bag was tied with nylon suturematerial. The bags were then thoroughly soaked and kneaded in water at room temperature until colour could no longer be squeezed from them. When each one had been dried and weighed two groups of six bags were tied together and suspended in the dorsal and ventral sacs of the rumen in the same way that the cotton threads were suspended. In this test all twelve bags were removed from the cow after $48 \mathrm{hr}$., again thoroughly soaked and kneaded in water, dried and weighed.

Diets. The experiments covered the period April-July, during which the cows were maintained on a succession of different diets. Details of the amounts of these diets form part of Table $\mathrm{I}$. The concentrates were a mixture in the proportions of ground dredge corn (oats and barley) roo g., linseed cake $5 \circ$ g., weatings 25 g., undecorticated groundnut cake $25 \mathrm{~g}$., decorticated groundnut meal $25 \mathrm{~g}$., limestone flour $2 \mathrm{~g}$. and common salt $1 \mathrm{~g}$. The hay was of a fairly coarse type.

\section{RESULTS}

Cotton. The rate of loss of dry matter from loops of cotton suspended in the rumen is conveniently studied by means of graphs showing, as a percentage of the initial weight, the reduction in the dry weight of cotton threads after different periods in the rumen (such a graph is shown in Fig. I). From graphs of this type, the time required for intermediate losses can be obtained by interpolation. Thus, Table $\mathrm{I}$ shows the time required for the loss of $10,20,30$ and $50 \%$ of the dry weight of cotton coils inserted in the dorsal and ventral sacs of the rumen. The data cover two cows on diets of unground and ground hay, alone and with concentrates. 
Table I. Summary of results of experiments on the loss of weight of cotton threads suspended in the dorsal and ventral sacs of the rumen

\begin{tabular}{|c|c|c|c|c|c|c|c|c|c|c|c|c|}
\hline \multirow[b]{3}{*}{ Cow } & \multirow[b]{3}{*}{$\begin{array}{l}\text { Exp. } \\
\text { no. }\end{array}$} & \multirow{2}{*}{\multicolumn{3}{|c|}{ Diet (kg./day) }} & \multicolumn{7}{|c|}{$\begin{array}{l}\text { Time required for breakdown of various } \\
\text { percentages of dry weight of cotton (hr.) }\end{array}$} & \\
\hline & & & & & \multicolumn{4}{|c|}{ Dorsal sac } & \multicolumn{3}{|c|}{ Ventral sac } & \\
\hline & & Hay & $\begin{array}{c}\text { Ground } \\
\text { hay }\end{array}$ & $\begin{array}{l}\text { Concen- } \\
\text { trates }\end{array}$ & 10\% & $20 \%$ & $30 \%$ & $50 \%$ & $10 \%$ & $20 \%$ & $30 \%$ & $50 \%$ \\
\hline \multirow[t]{6}{*}{ W } & I & $8 \cdot 2$ & - & - & $(55)$ & (73) & $(98)$ & $(140)$ & $2 \mathrm{I}$ & 25 & 28 & 33 \\
\hline & 2 & $8 \cdot 2$ & - & - & 35 & 50 & 62 & 87 & 14 & 17 & 22 & 27 \\
\hline & 3 & - & $8 \cdot 2$ & - & 36 & 51 & 59 & (75) & 22 & 29 & 34 & 44 \\
\hline & 4 & - & $8 \cdot 2$ & - & 60 & 86 & IIO & I30 & 30 & 54 & 67 & (8o) \\
\hline & 5 & $6 \cdot 8$ & - & $2 \cdot 7$ & 41 & 49 & 63 & 85 & 16 & 20 & 24 & 30 \\
\hline & 6* & $6 \cdot 8$ & - & $2 \cdot 7$ & 54 & (8o) & $(107)$ & $(140)$ & 15 & 19 & 22 & (3I) \\
\hline \multirow[t]{6}{*}{$\mathbf{Y}$} & $\mathbf{I}$ & $9 \cdot I$ & - & 4.5 & $4 I$ & $5^{2}$ & 76 & I 5 & I 8 & 25 & 30 & 39 \\
\hline & 2 & $9^{\cdot I}$ & 一 & 4.5 & $5 I$ & 68 & 88 & 124 & $2 \mathrm{I}$ & 28 & 35 & 45 \\
\hline & 3 & 一 & $9^{\cdot I}$ & 4.5 & 114 & $(\mathrm{r} 40)$ & $(\mathrm{I} 40)$ & $\left(x_{40}\right)$ & 30 & 34 & 37 & 50 \\
\hline & 4 & - & $9^{\cdot I}$ & $4 \cdot 5$ & 53 & 76 & 103 & 130 & 19 & 26 & 32 & 43 \\
\hline & 5 & $10 \% 4$ & 一 & - & 27 & $4 I$ & 47 & 59 & 22 & 27 & 32 & 36 \\
\hline & $6 *$ & 10.4 & - & - & 35 & 53 & 69 & $(103)$ & 19 & 27 & 33 & 43 \\
\hline
\end{tabular}

* Shown in Fig. 1 .

Values in parentheses are those obtained by extrapolation.
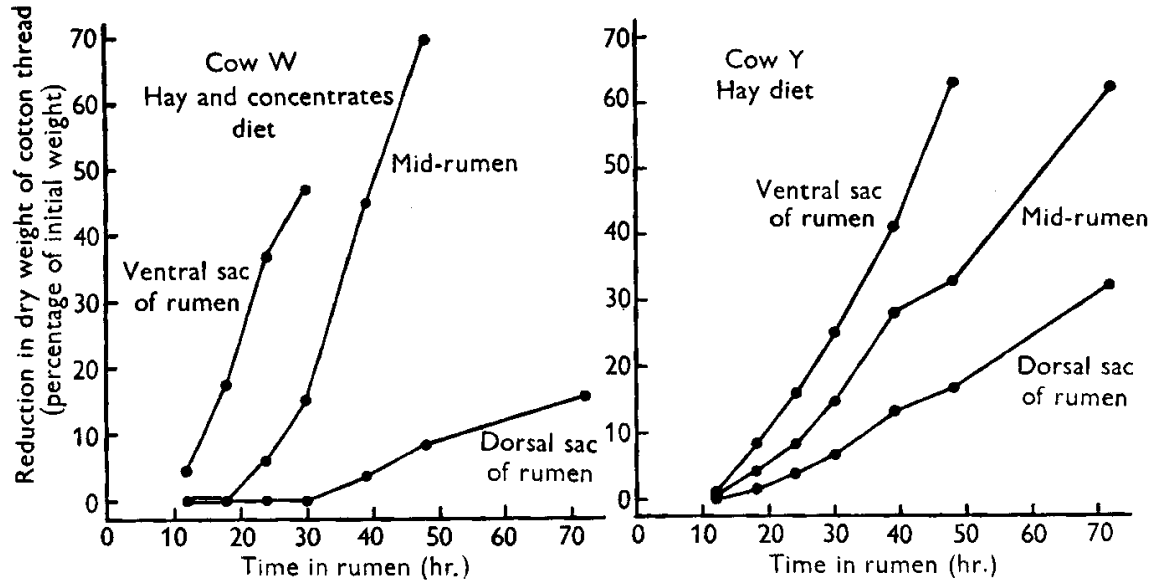

Fig. I. Exp. 6. Values for the reduction in the dry weight of cotton thread after suspension for various periods of time in the ventral sac, mid-rumen and dorsal sac of the rumen of two cows.

It was found that after $70 \%$ of the dry matter had been lost from a cotton coil, the coil ceased to be recognizable and tended to break apart during removal from the rumen. Figures of reductions in dry weight above $70 \%$ were therefore discarded. In some instances the duration of the experiment was insufficient for some of the higher levels of loss to be reached. Extrapolation was used to obtain tentative figures for such losses and in Table I figures obtained by extrapolation have been indicated.

A constant feature of every experiment was that coils of cotton were broken down at a faster rate in the ventral sac than in the dorsal sac of the rumen. There was also a tendency for the rate of breakdown of cotton in both sacs to be slower when the cows received ground hay than when the hay was given unground. No marked or 
consistent change in the rate of breakdown of cotton resulted from the addition of concentrates to all-hay diets.

In Exp. 6 (Table I, Fig. I) an additional group of cotton coils was suspended equidistant between the groups in the dorsal and ventral sacs of the rumen. In this position the rate of breakdown of cotton was clearly intermediate between the slow rate in the dorsal sac and the rapid rate in the ventral sac (Fig. I).

While the cows were maintained on any one diet the rates of breakdown of cotton in the dorsal and ventral sacs of the rumen tended to vary together. For example, in both sacs of cow W cotton was invariably broken down more rapidly in Exp. 2 than in Exp. I (Table I).

Hay. With hay the mean losses of dry matter after $48 \mathrm{hr}$. from six bags in each part of the rumen in two experiments were:

\begin{tabular}{|c|c|c|}
\hline \multirow[b]{2}{*}{ Position in rumen } & \multicolumn{2}{|c|}{$\begin{array}{l}\text { Mean loss of hay dry matter } \\
\text { from six bags }(\%)\end{array}$} \\
\hline & Exp. I & Exp. 2 \\
\hline Dorsal sac & I I·4 & $\mathrm{Ix} \cdot 7$ \\
\hline Ventral sac & $32 \cdot I$ & $34^{-8}$ \\
\hline
\end{tabular}

\section{DISCUSSION}

Hoflund et al. (1948) used an arbitrary method of assessing the breaking strain of cotton threads as a measure of the degree of breakdown that had taken place in the rumen of sheep. By means of a table of points varying according to the breaking strain and nature of the residue of threads on successive days after insertion into the rumen, they obtained a single value indicative of the rate of breakdown of the cellulose of cotton. Balch \& Johnson (unpublished data) found that when measured by attachment of weights the breaking stress of cotton varies considerably at different points on one thread. It is therefore preferable to assess the breakdown of cotton by weighing clean dry threads before and after suspension in the rumen. This simple method gives good agreement between duplicates.

In no test were cotton threads broken down as rapidly in the dorsal as in the ventral sac of the rumen. In the ventral sac of the rumen the dry weight of cotton thread was almost always reduced twice and sometimes three times as rapidly as in the dorsal sac. When the hay, in diets entirely or largely composed of hay, was ground, the rate of breakdown of cotton, particularly in the ventral sac of the rumen, tended to be less rapid than when the hay was unground. It was found in a previous experiment with the same cows on diets differing only in the nature of the concentrates (Balch, 1950) that whereas the digesta of the ventral parts (reticulum) of the reticulo-rumen contained only $5-6 \%$ dry matter when long hay was being fed, grinding the hay raised the dry-matter content of these digesta to $10 \%$. In that experiment, the contents of dry matter in digesta from the dorsal sac of the rumen were $13 . \mathrm{I}$ and $14.4 \%$ when the hay was long and 13.4 and $15.6 \%$ in cows $\mathrm{W}$ and $\mathrm{Y}$ respectively when the hay was ground. In that experiment, cow $\mathrm{Y}$ was receiving a concentrate mixture of dried skim milk and starch in contrast to the more usual mixture used for the experiment described in this paper. Measurements of the digestibility of the 
ground and unground hay diets and of the rate of passage of hay showed (Balch, 1950) that', though the rate of passage of ground hay through the reticulo-rumen tended to be more prolonged than that of unground hay, grinding depressed the faecal digestibility coefficients for crude fibre, particularly in cows receiving concentrates in addition to hay. These observations confirmed most earlier reports of the digestibility of ground hay (e.g. Kellner, I 907; Forbes, Fries \& Bramen, 1925; Bechdel, Williams \& Jeffries, 1927; Morrow \& LaMaster, 1929; Olson, I930 and Heller, Wall \& Briggs, I94I).

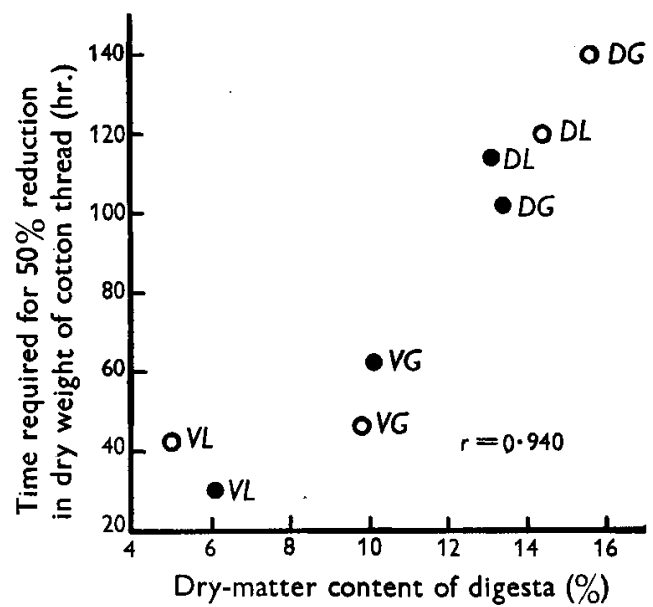

Fig. 2. Relationship between the time required for $50 \%$ loss of dry weight of cotton thread in the rumen (each value is the mean of two experiments) and mean values for the dry-matter content of the digesta in different parts of the reticulo-rumen, based on repeated samplings over to days (Balch, 1950). Values for cow W, $O$, and cow Y, $O$, are indicated and letters show values from the ventral $(V)$ and dorsal $(D)$ region of the reticulo-rumen and whether the hay of the diet was long $(L)$ or ground $(G)$. Cow $\mathrm{Y}$ received concentrates.

The experiments here reported suggested that the breakdown of cellulose in the reticulo-rumen was less rapid in dry than in wet digesta. In Fig. 2 are plotted the times required for the breakdown of $50 \%$ of the dry weight of cotton threads against a mean figure for the dry-matter content of the digesta in that part of the reticulorumen where the coils of cotton were suspended. The most accurate mean figures available for the dry-matter content of these digesta were those obtained from forty to fifty determinations on the same cows over periods of Io days, reported earlier (Balch, 1950) and quoted above. In the experiments reported in this paper a small number of determinations confirmed that the dry-matter contents of the various digesta were within the range observed in the earlier experiments, and that the percentages of dry matter in the contents of the reticulum and ventral sac of the rumen were very similar, but for Fig. 2 the earlier figures were used as the best available estimate. Fig. 2 shows that, irrespective of cow, position in the reticulo-rumen or type of diet, the time required for the breakdown of cellulose bore a positive correlation $(r=+0.940$, D.F. $=7)$ significant at the $\mathrm{I} \%$ level, to the dry-matter content of the surrounding digesta.

Feeding ground hay produced a higher dry-matter content of digesta in all parts of the reticulo-rumen than feeding unground hay, and a silk-bag experiment showed 
that the rate of breakdown of the total dry matter of ground hay was, like the rate of breakdown of cellulose, more rapid in the ventral than in the dorsal sac of the rumen. The crude fibre of ground hay, therefore, might be expected to have a lower faecal digestibility than that of unground hay, although any tendency to a lower digestibility might be modified or even reversed by a second factor, namely changes in the rate of passage of the hay. It is possible that a longer reaction time might be compensated by a decreased velocity of reaction (Balch, 1950).

The rumen fistulas were not completely airtight during these experiments and aerobic conditions may have affected the rate of breakdown of cellulose in the dorsal, as compared with the ventral, sac of the rumen; this seems improbable, however, in view of earlier results (Balch, 1950) which showed that fistulated cows digested crude fibre as efficiently as normal cows.

It is unlikely, therefore, that the observed differences in the rate of breakdown of cellulose and fibre in different parts of the rumen were due to any abnormality occasioned by the fistula.

\section{SUMMARY}

I. Coils formed of $3 \mathrm{~m}$. of cotton thread were suspended in the rumen of two fistulated Shorthorn cows and the rate of breakdown was estimated by measuring reductions in the dry weight of the coils.

2. The rate of breakdown of cellulose in the rumen of cows fed a diet of $(\dot{a})$ unground hay, $(b)$ ground hay, $(c)$ unground hay with concentrates, or $(d)$ ground hay with concentrates was much faster in the ventral than in the dorsal sac of the rumen.

3. The rate of breakdown of cellulose in the reticulo-rumen was closely related to the dry-matter content of the surrounding digesta; a low dry-matter content favoured the rapid breakdown of cellulose.

4. The rate of breakdown of the dry matter of hay suspended in the rumen in silk bags was also faster in the ventral than in the dorsal sac of the rumen.

5. It is suggested that the increases in the dry-matter content of the reticulorumenal digesta which normally accompany the feeding of ground hay constitute a major factor responsible for the lower digestibility of the crude fibre of ground hay as compared with that of unground hay.

We wish to thank Dr S. Bartlett for his help and encouragement with this problem.

\section{REFERENCES}

Balch, C. C. (1950). Brit. F. Nutrit. 4, 36 I.

Balch, C. C. \& Johnson, V. W. (1948). Vet. Rec. 60, 446.

Bechdel, S. I., Williams, P. S. \& Jeffries, C. D. (1927). Bull. Pa. agric. Exp. Sta. no. 213, p. 18.

Forbes, E. B., Fries, J. A. \& Bramen, W. W. (1925). F. agric. Res. 31, 987.

Heller, V. G., Wall, R. \& Briggs, H. M. (1941). Tech. Bull. Okla. agric. Exp. Sta. no. Io.

Hoflund, S., Quin, J. I. \& Clark, R. (1948). Onderstepoort F. vet. Sci. 23, 395.

Kellner, O. (1907). Die Ernährung der Landwirtschaftlichen Nutztiere, 4th ed. Berlin: Paul Taray.

Morrow, K. S. \& LaMaster, J. P. (1929). Bull. S. C. agric. Exp. Sta. no. 25.

Olson, T. M. (1930). Bull. S. Dak. agric. Exp. Sta. no. 252, p. 42.

\section{EXPLANATION OF PLATE}

P1. x. A coil formed of $3 \mathrm{~m}$. of cotton thread, supported on nylon suture-material. A numbered tag is fastened to the nylon and a loop provides a means of attachment to an anchor. 
C. C. Balch and V. W. JoHnson. Rate of breakdown of cellulose

Plate I IN THE RUMEN

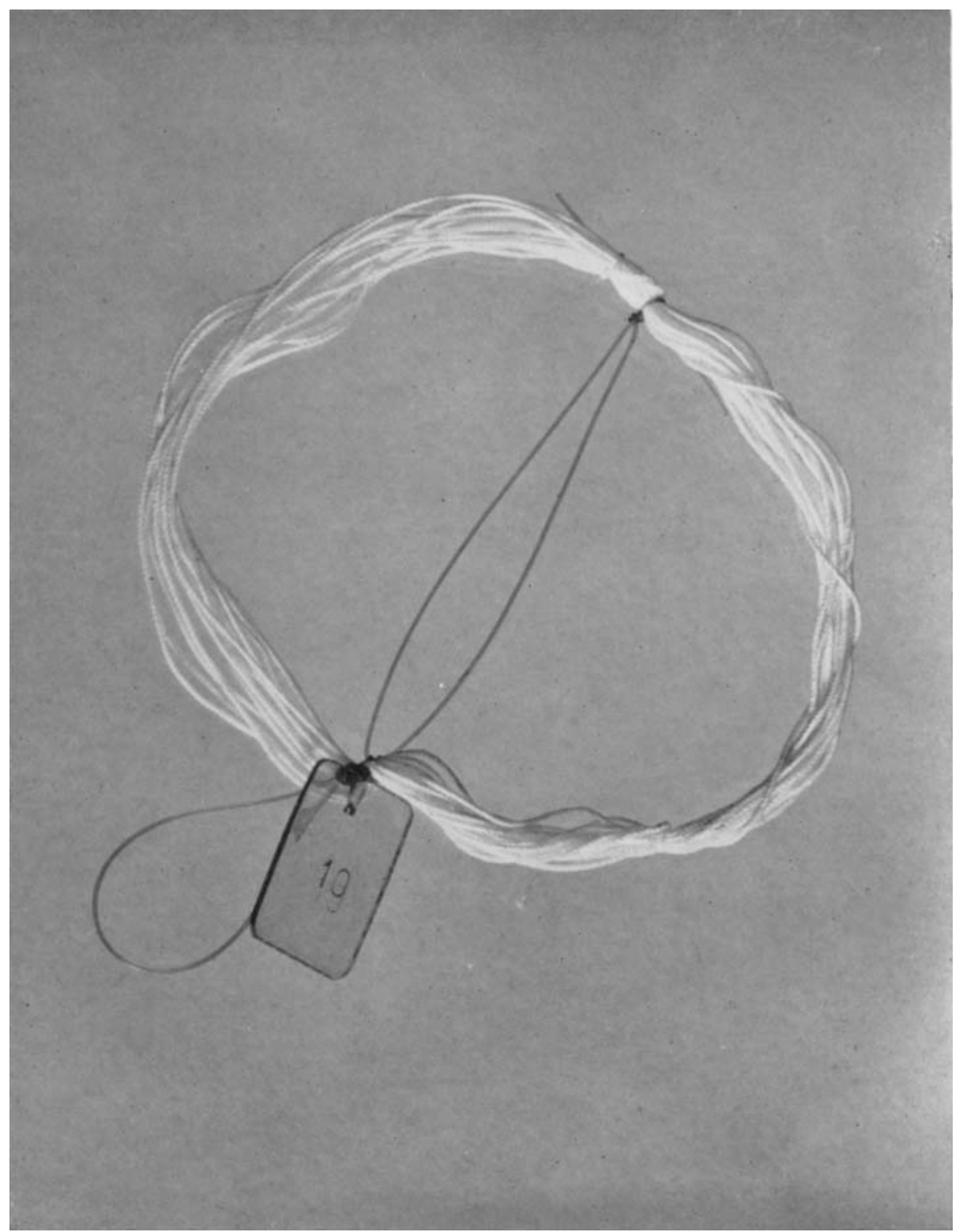

British Fournal of Nutrition, Vol. 4, No. 4 